\title{
Ibm Pelatihan Pengelolaan Data Siswa Menggunakan Ms Access Pada Guru Dan Karyawan Di SD Kristen Bala Keselamatan Semarang
}

\author{
Novita Kurnia Ningrum ${ }^{1}$, Cahaya Jatmiko ${ }^{2}$, Defri Kurniawan ${ }^{3}$, Daurat Sinaga ${ }^{4}$ \\ ${ }^{1234}$ Teknik Infromatika Fakultas Ilmu Komputer Universitas Dian Nuswantoro \\ 1'novita.kn@dsn.dinus.ac.id, ${ }^{2}$ cahayajatmiko@dsn.dinus.ac.id, ${ }^{3}$ defrikurniawan@dsn.dinus.ac.id, \\ ${ }^{4}$ dauratsinaga@dsn.dinus.ac.id
}

\begin{abstract}
Abstrak
SD Kristen Bala Keselamatan terletak di Jalan Dr. Cipto No.64B Kelurahan Bugangan Kecamatan Semarang Timur Kota Semarang. Sesuai dengan Peraturan Menteri Pendidikan dan Kebudayaan Tahun 2016 tentang Permendikbud No 21 Tahun 2016 Tentang Standar Isi Pendidikan Dasar dan Menengah yang berkaitan dengan proses pengelolaan data siswa. Saat ini SD Kirsten Bala Keselamatan Kota Semarang sudah memiliki Laboratorium komputer. Akan tetapi saat ini pengelolaan data akademik dan administrasi siswa masih dilakukan secara manual mencatat di buku. Selain kurangnya tenaga pengajar dan tenaga adminstrasi, guru dan staf yang bertugas di SD Bala Keselamatan masih belum memiliki kemampuan khusus dalam mengelola data siswa secara terkomputerisasi. Oleh karena itu, maka pada pengabdian masyarakat dengan skim Ipteks bagi Masyarakat ini akan diberikan pelatihan dengan materi pengelolaan data siswa menggunakan Microsoft Office Access. Kegiatan dilaksanakan dalam waktu satu hari dengan materi database dan Microsoft Office Access. Peserta yang mengikuti kegiatan sebanyak 12 guru dan karyawan yang $75 \%$ diantaranya belum mengenal dan belum dapat membuat database dan menggunakan Microsoft Office Access. Setelah kegiatan dilaksanakan, dari 12 guru dan karyawan yang telah mengikuti pelatihan, menunjukkan bahwa 5 orang diantaranya sudah dapat membuat database menggunakan Microsoft Office Access, 6 orang dapat menggunakan Microsoft Office Access dan 1 orang masih membutuhkan pendampingan menggunakan Microsoft Office Access.
\end{abstract}

Kata kunci: 3-5 kata kunci, pelatihan, teknologi, komputer

\begin{abstract}
SD Kristen Bala Keselamatan is located at Jalan Dr. Cipto No.64B Bugangan Village, East Semarang District, Semarang City. In accordance with the Regulation of the Minister of Education and Culture of 2016 concerning Permendikbud No. 21 of 2016 concerning Basic and Secondary Education Content Standards relating to the process of managing student data. Currently, Kirsten Elementary School, Semarang City Salvation Army, already has a computer laboratory. However, currently the management of student academic and administrative data is still done manually taking notes in books. Apart from the lack of teaching and administrative staff, teachers and staff on duty at SD Bala Salvation School still do not have special abilities in managing student data in a computerized manner. Therefore, in this community service with the science and technology scheme for the community, training will be given on student data management using Microsoft Office Access. Activities carried out within one day with database material and Microsoft Office Access. Participants who took part in the activity were 12 teachers and employees, $75 \%$ of whom could not create a database and use Microsoft Office Access. After the activity was carried out, of the 12 teachers and employees who had participated in the training, it was shown that 5 of them were able to create a database using Microsoft Office Access, 6 people could use Microsoft Office Access and 1 people still needed assistance using Microsoft Office Access.
\end{abstract}

Keywords: 3-5 keywords, workshop, technology, computer 


\section{PENDAHULUAN}

SD Kristen Bala Keselamatan terletak di Jalan Dr. Cipto No.64B Kelurahan Bugangan Kecamatan Semarang Timur Kota Semarang. Sesuai dengan Peraturan Menteri Pendidikan dan Kebudayaan Tahun 2016 tentang Permendikbud No 21 Tahun 2016 Tentang Standar Isi Pendidikan Dasar dan Menengah yang berkaitan dengan proses pengelolaan data siswa [1]. Peraturan yang berlaku saat ini menghimbau paada seluruh sekolah untuk mensikronkan data seluruh data siswa dengan sistem Dapodik setiap Daerah. Dengan demikian seluruh sekolah termasuk SD Kristen Bala Keselamatan Kota Semarang juga harus dapat mensinkronkan data siswa pada sistem dapodik tersebut.

Saat ini SD Kirsten Bala Keselamatan Kota Semarang sudah memiliki Laboratorium komputer. Akan tetapi saat ini pengelolaan data akademik dan administrasi siswa masih dilakukan secara manual mencatat di buku. Pencatatan manual tersebut rawan adanya kesalahan penulisan data dan kehilangan data. Adapun kendala yang dihadapi oleh SD Bala Keselamatan Kota Semarang dalam pengelolaan data akademik dan administrasi siswa diataranya adalah karena minimnya tenaga administrasi dan tenaga mengajar yang bertugas di sekolah tersebut. Sejauh ini sebagaian tenaga pengajar merangkap sebagai tenaga administrasi untuk mengelola data administrasi dan data pendidikan siswa. Selain kurangnya tenaga pengajar dan tenaga adminstrasi, guru dan staf yang bertugas di SD Bala Keselamatan masih belum memiliki kemampuan khusus dalam mengelola data siswa secara terkomputerisasi.

Oleh karena permasalahan di atas, maka pada pengabdian masyarakat dengan skim Ipteks bagi Masyarakat ini akan diberikan pelatihan dengan materi pengelolaan data siswa menggunakan Ms. Office Access. Menurut penelitian oleh Amiruddin yang menyatakan bahwa Ms. Office Access dengan fitur management database relational sangat membantu dalam mengelola data-data yang ada sehingga dapat terintegrasi antara satu dengan yang lainnya [2]. Salah satu tujuan pengelolaan database diantara adalah agar memudahkan penyusunan arsip dan memudahkan dalam pencarian data dalam bentuk elektronik. Sebagaimana yang disampaikan oleh Oktaviani dalam penelitiannya yang menyatakan bahwa Ms. Office Access dapat digunakan untuk memudahkan arsip yang tidak tersusun agar dapat tersistematis dan Ms. Office Access merupakan program database digunakan untuk pengolahan berbagai jenis data [3].

Menurut penelitian yang ada, bahwa pengelolaan data akademik dan administrasi siswa yang tidak rapi disebabkan minimpnya pengetahuan yang diiliki oleh tenaga pengajar dan staf yang bertugas di sekolah bersangkutan. Adanya sumberdaya software dan hardware yang dimiliki oleh sekolah tidak menjamin adanya kemampuan mengelola data akademik dan administrasi. Hal tersebut disebabkan oleh tenaga pengajar dan staf belum memiliki kemampuan untuk menggunakannya sesuai dengan kebutuhan [4].

Berdasarkan pemaparan di atas, maka pada pengabdian masyarakat ini akan dilakukan pelatihan bagi tenaga pengajar dan staf di SD Kristen Bala Keselamatan Kota Semarang. Adapun materi yang akan diberikan dalam pelatihan adalah mengenai pengelolaan database siswa menggunakan Ms. Office Access. Dengan adanya pelatihan ini dihaapkan dapat meningkatkan kemampuan tenaga pengajar dan staf dalam menggunakan Ms. Office Access untuk mengelola data siswa. Selanjutnya tenaga pengajar dan staf dapat menyusun informasi dan laporan yang terintegrasi dan rapi 
sehingga dapat menunjang kualitas pendidikan di SD Kristen Bala Keselamatan Kota Semarang.

\section{METODE PELAKSANAAN}

Pelaksanaan kegiatan pengabdian masyarakat ini melalui beberapa tahapan pelaksanaan, yang pertama analisa masalah, kedua analisa kebutuhan dan ketika pelaksanaan pelatihan.

2.1. Analisa Masalah

Berdasarkan pemaparan latar belakang masalah di atas, terdapat beberapa masalah yang dihadapi oleh SD Kristen Bala Keselamatan Kota Semarang berkaitan dengan pengelolaan data akademik dan administrasi. Masalah pertama, minimnya tenaga pengajar dan staf yang bertugas, sehingga masih terjadi rangkap tugas baik sebagai pengajar sekaligus sebagai staf. Permasalahan yang kedua, proses pengelolaan data akademk dan admistrasi masih dicatat manual di buku, sehingga rawan terjadi kesalahan dalam penulisan dan kehilangan data. permasalahan ketiga, pengajar dan staf belum memiliki kemampuan untuk mengelola data akademik dan administrasi siswa secara terkomputerisasi.

\subsection{Analisa Kebutuhan}

Sejalan dengan pemaparan pada analisa masalah di atas, maka secara umum yang dibutuhkan oleh tenaga pengajar dan staf SD Kristen Bala Keselamatan Kota Semarang adalah sebagai berikut:

1. Diperlukan pelatihan untuk tenaga pengajar dan staf di SD Kristen Bala Keselamatan dalam megoperasikan komputer

2. Diperlukan pelatihan untuk tenaga pengajar dan staf di SD Kristen Bala Keselamatan dalam mengelola data akademik dan admisnistrasi siswa secara terkomputerisasi.

Untuk melaksanakan kegiatan pelatihan tersebut, maka diperlukan perangkat sebagai berikut:

1. Kebutuhan Hardware Spesifikasi hardware yang diperlukan untuk pelatihan ini adalah sebagai berikut:

- PC dengan processor minimal Core 2 duo, RAM min 1 GB

2. Kebutuhan Software

Spesifikasi software yang dibutuhkan adalah:

- Operating System Windows 8

- Microsoft Office, sp. Microsoft Office Access

3. Kebutuhan Modul

Adapun materi modul yang disampaiakan meliputi:

- pengenalan database

- pengenalan microsoft office access untuk pengelolaan database

- perancangan database menggunakan microsoft office access

\subsection{Pelaksanaan Kegiatan}

Pengabdian masyarakat dengan skema Ipteks bagi Masyarakat telah dilaksanakan pada bulan Januari 2019 di SD Kristen Bala Keselamatan Kota Semarang. Adapun tahapan pelaksanaan kegiatan adalah sebagai berikut:

1. Pre Tes

Sebelum diberikan pelatihan pada anggota Dharmawanita Provinsi Jawa Tengah, dilakukann Pre Test terlebih dulu untuk mengetahui sejauh mana pemahaman peserta pelatihan terhadap materi yang akan disampaiakan. Pre test yang diberikan berupa beberapa pertanyaan dalam bentuk kuesioner yang dijawab oleh seluruh peserta pelatihan. Adapun hasil pre test adalah sebagai berikut:

1. Dari 12 guru dan staf pengajar di SD Kristen Bala Keselamatan, $75 \%$ diantaranya belum mengenal micros Microsoft Office Access untuk pengelolaan data siswa. 
2. Guru dan staf pengajar yang mamapu menggunakan Microsoft Office, baru mampu mengaplikasikan Micrososft Word untuk membuat dokumen.

3. Tenaga guru dan staf pengajar belum dapat menggunakan Microsoft Office Access

4. Tenaga guru dan staf pengajar belum dapat merancang database menggunakan Microsoft Office Access

2. Pelaksanaan Pelatihan

Pelatihan dilaksanakan dengan 2 metode, yaitu teori dan praktikum.

a. Secara Teoritis

Setiap peserta mendapatkan materi berupa 1 bundel materi dan nara sumber memberikan penjelasan secara rinci untuk setiap materi yang telah tercantum di bundel materi pelatihan. Isi materi berupa pengenalan awal fungsi dari Microsoft Office Access, materi dasar database manajemen sistem, membuat lembar kerja baru menggunakan Microsoft Office Access, membuat dan mengelola database menggunakan Microsoft Office Access.

b. Secara Praktikum

Peserta mendapatkan kesempatan untuk mempraktikkan secara langsung materi yang disampaikan oleh narasumber melalui $P C$ yang dioperasikan langsung oleh peserta pelatihan.

\section{HASIL DAN PEMBAHASAN}

Capaian hasil dari kegiatan pengbdian masyarakat skema IbM ini berupa modul yang diberikan dalam bentuk hardcopy maupun soft copy kepada anggota peserta pelatihan yaitu Tenaga Pengajar dan staf SD Kristen Bala Keselamatan Kota Semarang.

Luaran yang dicapai adalah mengupload hasil pengabdian masyarakat skema Internet bagi Masyarakat di SD Kristen Bala Keselamatan Kota Semarang pada channel youtube Abdimasku. Dan bisa di akses di link youtube: https://www.youtube.com/watch?v=7pZL7pa_5r4\&feature=youtu.be. Dan telah disubmit ke jurnal ABDIMASKU LPPM Universitas Dian Nuswantoro.

Hasil evaluasi setelah pelaksanaan kegiatan adalah:

1. Peserta yang telah mengikuti kegiatan sudah mengenal dan memahami database dan kegunaan database untuk pengelolaan data siswa.

2. Peserta yang telah mengikuti kegiatan sudah mampu membuat database menggunakan microsoft access dengan panduan dari tutor.

3. Guru dan staf menjadi lebih mudah dalam mengelompokkan data dan mengelolanya sehingga dapat menghasilkan laporan data akademik yang lebih baik.

Dari 12 guru dan karyawan yang telah mengikuti pelatihan, menunjukkan bahwa 5 orang diantaranya sudah dapat membuat database menggunakan Microsoft Office Access, 6 orang dapat menggunakan Microsoft Office Access dan 1 orang masih membutuhkan pendampingan menggunakan Microsoft Office Access. Perbandingan kondisi peserta sebelum dan setelah mengikuti pelatihan ditunjukkan pada Tabel 1 di bawah ini. 
Tabel 1 Perbandingan Peserta Sebelum Mengikuti dan Setelah Mengikuti Pelatihan

\begin{tabular}{|c|c|c|c|}
\hline Kondisi & $\begin{array}{c}\text { Dapat } \\
\text { Menggunakan Ms } \\
\text { Access }\end{array}$ & $\begin{array}{c}\text { Dapat Merancang } \\
\text { database } \\
\text { menggunakan } \\
\text { Ms.Access }\end{array}$ & $\begin{array}{c}\text { Membutuhkan } \\
\text { Pendampingan } \\
\text { menggunakan } \\
\text { Ms.Access }\end{array}$ \\
\hline $\begin{array}{c}\text { Sebelum } \\
\text { Pelatihan }\end{array}$ & 0 & 0 & 12 orang \\
\hline $\begin{array}{c}\text { Setelah } \\
\text { Pelatihan }\end{array}$ & 5 orang & 6 orang & 1 orang \\
\hline
\end{tabular}

Berdasarkan Tabel 1 di atas menunjukkan bahwa pelatihan yang telah dilaksanakan sudah dapat membantu memberikan ketrampilan pada guru dan staf pengajar di SD Kristen Bala Keselamatan dalam mengelola data siswa menggunakan Miceosoft Office Access.

\section{KESIMPULAN DAN SARAN}

Berdasarkan kegiatan yang sudah kami laksanakan, dapat disimpulkan bahwa saat penggunaan microsoft office access sangat membantu tenaga pengajar dan staf di SD Kristen Bala Keselamatan mengelola data siswa. Saat ini tenaga pengajar dan staf di SD Kristen Bala Keselamatan sudah mampu membuat database menggunakan microsoft access. Untuk kegiatan selanjutnya, diperlukan pengelolaan database akademik siswa yang diintegrasikan dengan laporan hasil belajar siswa.

\section{DAFTAR PUSTAKA}

[1] Lampiran Permendikbud No 21 Tahun 2016, "Standar Isi Pendidikan Dasar dan Menengah," 2019. [Online]. Available: https://bsnp-indonesia.org/standar-isi/.

[2] N. Amiruddin, "Sistem Informasi Perpustakaan Berbasis Ms Access pada Jurusan Administrasi Niaga Politeknik Negeri Ujung Pandang," Jurnal Sainsmat, p. 175195, 2015.

[3] A. H. Oktaviani and M. Nelisa, "PEMBUATAN PANGKALAN DATA ARSIP MENGGUNAKAN MICROSOFT ACCESS PADA SESI PEMBERITAAN DI LLP RRI BUKIT TINGGI," Jurnal Ilmu Informasi dan Ilmu Kearsipan, vol. 4, no. 1, 2015.

[4] N. Kurnia Ningrum, Y. Parti Astuti and U. Sudibyo, "IbM PENERAPAN MICROSOFT OFFICE EXCEL UNTUK MENUNJANG PROFESIONALISME GURU DALAM PENGELOLAAN NILAI SISWA DI SD SYAHIDIN SEMARANG," Jurnal Abdimasku, 2019. 